\title{
Dictators and Ultimatums in an Egalitarian Society of Hunter-Gatherers, the Hadza of Tanzania
}

\author{
Frank Marlowe
}

\section{INTRODUCTION}

Game theory and the empirical results of game experiments provide insight into human behavior, especially cooperative behavior. It has often been suggested that the foundation for much human cooperation is the widespread food sharing observed among huntergatherers (Isaac 1978; Cosmides and Tooby 1992; McGrew and Feistner 1992; Boehm 1999). To investigate this proposition, I enlisted one of the few remaining societies of active hunter-gatherers, the Hadza of Tanzania, to play two related games, the Ultimatum Game (UG) and the Dictator Game (DG) (see box below for an explanation of these games).

Box: The Ultimatum Game, Dictator Game, and Standard Economic Theory

In the UG, a proposer is asked to divide a sum of money with a caption is okay responder. If the responder accepts the proposer's offer the money is so divided, but if the responder rejects the offer, both players get nothing. The UG elicits the proposer's propensity to hoard or share and the responder's propensity to accept or punish. The DG is played exactly like the UG except that the responder does not get to reject offers. The UG reveals how people behave when there are potential costs, whereas the DG reveals how willing people are to share without such costs, thus revealing more about internalized norms of fairness. Proposers' offers in the DG, therefore, help explain their offers in the UG.

Thanks to the Hadza for always being so tolerant. Thanks to the Tanzanian government (COSTECH) for permission to conduct research, the Hanbygotts for assistance, and the MacArthur Foundation for funding. 


\section{(Continued)}

According to Standard Economic Theory, responders in the UG should accept any offer above zero, since something is better than nothing. Proposers should therefore, offer the smallest non-zero amount allowed by the game protocol. Yet experiments in complex societies show that proposers tend to offer much more than this; the modal offer is usually 50 percent (Camerer 2003). Such high offers seem irrational, unless responders often reject offers above zero. And they do; offers of 20 percent usually have about a 50 percent chance of being rejected (Camerer 2003). This makes the responders the irrational ones.

How hunter-gatherers play these games is interesting for several reasons. First, if we think there is a universal psychology mediating sharing and coop eration, then it likely evolved in the context of hunting and gathering, and we'd expect to see hunter-gatherers exhibit something closer to the baseline predisposition than would people in the evolutionarily novel environments of complex societies. Second, hunter-gatherers should be little influenced by markets that regulate exchange. Third, the ethnographic literature on hunter-gatherers is replete with accounts of a strong sharing ethic and widespread sharing of food, especially big game meat (Hadza-Woodburn 1998; Hawkes, O'Connell, and Blurton Jones 2001; Ju/'hoansi-Wiessner 1982; Lee 1984; Aka-Bahuchet 1990; Kitanishi 1998; Inuit—Smith 1985; Ache-Kaplan and Hill 1985; Murngin and Wik-mungkan-Peterson 1993).

Among foragers, much food sharing occurs within the household and is nepotistic, but certain foods are also shared outside the family. Sometimes one type of food is traded for another type, but most sharing does not meet the criterion of simultaneous, not-inkind trade. Occasionally, people will forage together and share both the work and the food, which could be an example of by-product mutualism. Among many foragers like the Hadza, however, a man will forage alone and bring game or honey back to camp to share, which is clearly not a case of by-product mutualism.

Evolutionary anthropologists have focused on three other explanations for widespread food sharing. (1) Tolerated scrounging proposes that individuals relinquish shares of food when the marginal value of those shares falls below the cost of defending them 
(Blurton-Jones 1984, 1987). (2) Delayed reciprocity proposes that individuals are predisposed to share their food with others so that others will give them food later on and minimize their risk of going without food on any given day (Kaplan and Hill 1985). (3) Costly signaling proposes that individuals gain mating or other advantages by freely giving food away because such generosity is an honest signal of their phenotypic quality when resources are difficult to acquire (Bird 1999; Hawkes and Bliege Bird 2002). Costly signaling has more to do with what motivates the forager to work, while tolerated scrounging and delayed reciprocity attempt to explain the pattern of food distribution.

Food transfers should be fairly evenly balanced (at least in terms of value) if reciprocity is important while they need not be with tolerated scrounging. Presuming the games elicit the same behavior as food sharing, we might predict people should be more generous givers in the games if food sharing is motivated by reciprocity or costly signaling than if it is motivated by tolerated scrounging. That is, if people are primed to give to signal their generosity, or to build cooperative partnerships, we might anticipate fair (equal) offers in the games (for a more detailed discussion of predictions based on food sharing hypotheses see (Marlowe n.d.)). I will return to the issue of whether the games do elicit the same behavior as food sharing in the discussion section.

Given that responders are able (and may be willing) to punish in the UG, we should expect higher offers in the UG than the DG. If a proposer can offer between 0 and 100 percent in increments of 10 percent, the rational offer (assuming standard preferences) would be 0 percent in the DG and 10 percent in the UG. However, if people often reject offers of 10 percent in the $\mathrm{UG}$, it is rational to offer enough to avoid rejection - with an acceptable degree of risk. But what is an acceptable degree of risk? And why should people reject offers of 10 percent, and why should the likelihood of rejection vary? These also are questions to which I return in the discussion section.

\section{STUDY POPULATION}

The Hadza are nomadic hunter-gatherers who live near Lake Eyasi in northern Tanzania and number about 1000 (Blurton-Jones 
et al. 1992), 300-400 of whom are full-time foragers. The other Hadza are part-time foragers and part-time laborers for farmers, or depend on tourist money or handouts from missionaries. The area is savanna-woodland receiving $300-600 \mathrm{~mm}$ of rain, almost all of which falls between November and May. Most Hadza camps are located in rocky hills where there are permanent water holes and a variety of game animals.

The Hadza have probably been in the area for a very long time. Stone artifacts, found in rock shelters show a continuous occupation over many thousands of years (Mabulla 1996). There have been other ethnic groups in the area for a long time as well. The Cushiticspeaking Iraqw have been farming in the highlands for at least 2,000-3,000 years (Sutton 1989). The Nilotic-speaking Datoga pastoralists and the Bantu-speaking Isanzu agro-pastoralists have been in the area for over 100 years (Newman 1995). Although there is a record of interaction with these other groups over the past century, consisting mainly of Hadza trading meat and honey for tobacco, iron, and beads, a high degree of Hadza autonomy has been maintained. This is reflected in the fact that the Hadza language, which is not at all related to any of the languages of their neighbors, is still spoken by all Hadza as their first language.

Virtually all Hadza today speak Swahili as a second language and many also know a third or fourth language. From the time they are about four or five, most Hadza children understand Swahili, only a handful of the oldest women have some difficulty. All other adults are fluent in Swahili even though women have fewer interactions with outsiders and leave the bush less often than men.

The Hadza are one of the most egalitarian societies in the ethnographic literature (Woodburn 1982). Adults are dominant over children and males over females, but even in this respect the differences are slight. There are no chiefs, no big men, no official titles or roles, no specialists of any kind. Very good hunters are usually more highly esteemed but even this is subtle. Occasionally some man who has a connection with missionaries or a government official may try to tell others what to do, but since no one likes to be bossed around, they simply get up and move to another camp or start a new camp when someone gets bossy. Being nomadic and lacking ownership of property means everyone is free to 'vote with their feet'.

Camp composition is flexible and camp population and location may change with the seasons or for a host of other reasons. Camps 
are referred to either by a place name or by the name of some man who is usually an older man who has long been married to a woman in the camp. Such a woman often has her parents or her sisters living with her, so the core of a camp is usually a group of related females. However, like most things in Hadza society, post-martial residence is quite flexible and depends on circumstances since descent is bilateral and kin are treated equally on mother's and father's side.

The Hadza I work with are full-time foragers who practice no agriculture. In 1995-96 only about 7 percent of calories consumed across five camps came from food gained through trade with their agro-pastoralist neighbors or missionaries and some camps were virtually 100 percent dependent upon foraging (Marlowe 2002). Women use simple digging sticks to dig for underground storage organs, or tubers, on an almost daily basis, while they gather berries seasonally, and collect baobab fruit when it falls to the ground. They usually go foraging in groups of 3-6 women. When they are digging for tubers, they often help each other lever boulders up out of the way and sometimes help each other dig up the same tuber.

Men do not do as much cooperative foraging as women. They carry their bows and arrows with them wherever they go and will shoot at most any mammal or bird, usually going alone on forays. During the late-dry season however, men will go hunting at night, waiting at the few permanent waterholes to ambush game that must come to drink. Because other predators like lions and leopards use the same strategy, night hunting is very dangerous and they always do this in pairs. Men also help each other track game once it has been hit if the hunter returns to camp before beginning to track. Men also use axes to break into beehives for wild honey and this they also usually do alone but sometimes go in pairs and sometimes go with their wives. Men also get baobab and berries but do not take them back to camp as frequently as women do.

About one-third of the food in the diet is consumed while out foraging, while the rest is taken back to camp where it is shared to varying degrees within the household and with other households. The most widely shared foods are big game. When a man kills a gazelle, he may bring the whole animal back to camp where it is divided up fairly equally among the households, especially if there are only a few households. When a man kills a giraffe, he cuts off as much meat as he can carry back to camp and then others go to the kill site to cut off their own shares. In addition to meat, honey is 
often shared widely with people outside the household. Even items like the tubers women dig and the berries people pick are sometimes shared back in camp with others who are not members of the forager's household.

Hadza men also scavenge from other predators, mostly lions, leopards, hyenas, and wild dogs, running them off their kills. Sometimes, the meat they scavenge is many days old and completely rotten and covered with maggots. They cook it and eat it and get stomachaches but value it nonetheless. The Hadza also dry meat to preserve it. One Hadza man kept dried meat hidden in the luggage rack of the Land Rover and ate from it for almost a month as we traveled from camp to camp. Rarely, however, do the Hadza bother to dry meat because it gets shared and eaten up so quickly.

Some Hadza live in or near a village and have some interaction with markets and money. Most of the Hadza I work with, however, live in the bush and have little such interaction. For example, many people in 1995 refused money, preferring gifts instead. This was especially true of women who rarely get to a village where they can use money. But change is coming rapidly, mainly in the form of tourism. By 1998, almost all Hadza, even in remote bush camps, were occasionally visited by tourists who paid money to see them. For this reason, many Hadza now prefer money to gifts.

\section{METHODS}

I used 2000 Tanzania shillings (\$3.08 at 1998 exchange rate) as the stakes in each game. Tanzania's per capita GDP equals \$650 (1995 est.), which means a day's wage equals $\$ 1.78$ (for a 7-day workweek). Thus, the stakes were 1.69 day's wage. These figures are skewed by the influence of Dar es Salaam; the wages in the area where the Hadza live would be much lower. Although we were asked to use one day's wage, I used 2000 shillings because it meant there would be ten easy units of 200 shilling bills. Wages have no meaning to the Hadza anyway, since only a very few have ever performed wage labor. A day's wage in the US is $\$ 78.36$ (per capita $\mathrm{GDP}=\$ 28,600,1997$ ) for a 7-day week. That means the stakes were $1 / 26$ th of a day's wage in the United States but in Tanzanian purchasing power equivalent to $\$ 132$ - perhaps twice that much in Hadzaland. 
I conducted the games in Swahili and played with one subject at a time inside a Land Rover with money laid out in front of us. The Hadza language only has words up to four, beyond that Swahili words have been borrowed. Because the Hadza are not very familiar with money or numbers I used the bills as a visual aid. I explained that I would talk about ten bills of money rather than 2000 shillings, which made it easier for them to add and subtract. For example, instead of having to calculate that 400 from 2000 left 1600 shillings, they could count the bills to see that two from ten left eight bills.

The game procedure was explained to each subject individually by reading a standard text in Swahili and providing further clarification when necessary. Next, I gave the subject a hypothetical offer and asked what the payoffs to the two players would be if the offer were accepted and if the offer were rejected. I repeated the trials until the subject appeared to understand and got the correct answers to four scenarios. The subject's comprehension was scored from one to three (three being highest) by the number of trials it took to get correct answers. Once a subject passed the tests, I told him or her that the real game was beginning. If in the role of player one (proposer), the subject was asked to make an offer. If assigned the role of player two (responder), the subject was told what the offer had been and asked whether he or she accepted or rejected the offer.

Deciding who would play and in which role is tricky in a nomadic population, where people come and go so frequently. I tried to assign roles randomly while also insuring everyone would have a partner in the same camp. First, I estimated the number of people who would play in each camp, roughly the number of resident adults. The first few to play were proposers. Thereafter, I decided the exact number of players who would be responders to those first few offers. In whatever order they arrived, responders were sequentially matched with the previous offers. After all offers had been responded to, the next few players were assigned the role of proposers again, and so on, repeating the process. This meant those waiting to play did not know which role they were going to be assigned and it meant my assignment of roles was not influenced by the identity of the players.

After playing, I asked subjects why they offered the amount they did or why they accepted or rejected an offer. I also asked responders what offer was the minimum they would have accepted. 
I paid everyone before leaving each camp. This meant that all players (with only two exceptions) were matched against others in the same camp. This was the only way to insure that all would receive their payoffs since it is not easy to find everyone a second time after leaving a camp. Some people might have been able to figure out who their partner had been by the time all had played if they asked who had made particular offers. The chances of that would be greater the smaller the camp, but I saw no sign that anyone ever knew who their partner had been, and I believe the subjects had complete confidence in the anonymity ( $\mathrm{AN}$ ) of the games.

\section{The Dictator Game}

I only played the DG with people once I had finished playing the UG in a camp. In the DG, I used beads instead of money. This accomplished three things. First, it meant I was not flooding the Hadza with quite so much money, a problem since it quickly goes to the neighboring agro-pastoralists who make and sell alcohol to the Hadza. Second, it allowed me to assess if there was any difference in subjects' understanding when bills with 200 written on them, were replaced by more familiar beads. Since beads did not seem to make it noticeably easier, I think it is legitimate to extrapolate from one game to the other. Third, even though the rules of the two games were carefully explained to subjects, using a different currency helped to further distinguish the games in people's minds.

I filled transparent plastic tubes with beads and laid ten tubes down in front of the subject. I used the ten units (tubes) as a visual aid in the trials to make subtraction easier for players. This amount of beads was worth roughly the same to the Hadza as was the 2000 shillings. Because different people prefer different colors of beads, I let the subjects choose which color or combination of colors to use.

\section{RESULTS}

\section{The Ultimatum Game}

I played with most adults in five different camps ranging in population from 16 to 134. Eight people played in camps where they were visiting, rather than living. There were fifty-five pairs of players, fifty-five males (twenty-seven proposers, twenty-eight responders) 


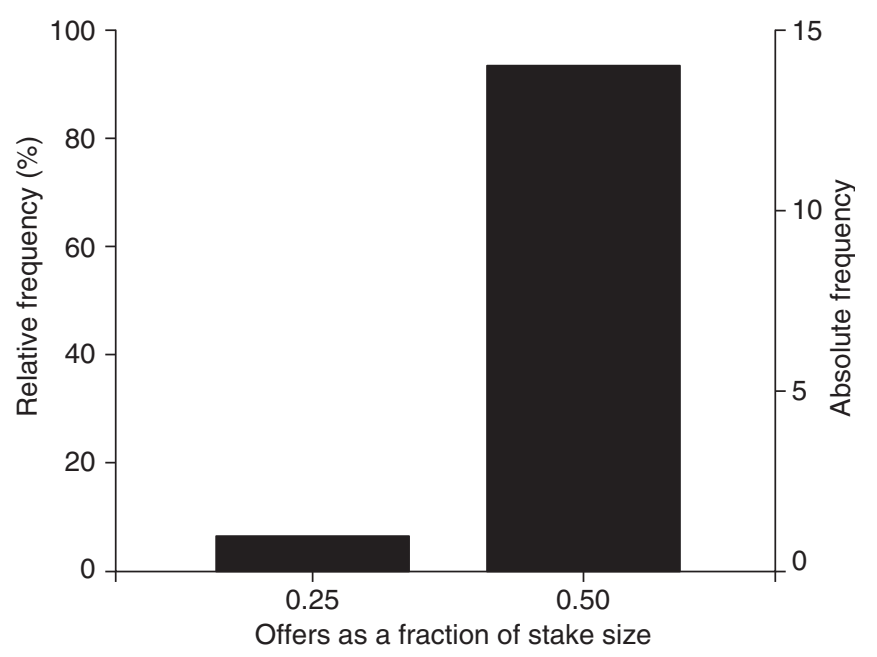

FIG. 6.1. LA UG offers

Note: Mode $=0.5$, mean $=0.48, \mathrm{SD}=0.065, n=15$, no rejections.

and fifty-five females (twenty-eight proposers, twenty-seven responders), with a mean age of 37.2 years $(17-70, \mathrm{SD}=14.4)$. In stark contrast to the strong modal offer of 0.5 of the stakes $(50$ percent) typical of complex societies, as represented by Los Angeles (Figure 6.1), the Hadza modal offer was 0.2 (20 percent) (mean $=0.33, \mathrm{SD}=0.17, n=55)($ Figure 6.2).

In complex societies, where there are only a few low offers, the mode is usually higher than the mean, while the opposite is true of the Hadza and Machiguenga (Henrich 2000). The mode, especially a pronounced one, is the more meaningful statistic if one is interested in group norms and cross-cultural variation. Next to the Machiguenga, the Hadza modal offer was the lowest of all smallscale societies so far tested (Figure 6.3), but note that eight of the fifteen small-scale societies (53.3 percent) in this volume had modal offers below 0.5 (50 percent).

There were thirteen rejections among the Hadza. Not surprisingly, rejections were negatively correlated with offers $(r=-0.485$, $p=0.000, n=55)$. The rejection rate was 24 percent and the mean offer rejected was 18 percent (range $0-40$ percent) (Figure 6.4). This contrasts with the Machiguenga where there was only one rejection. Thus, while the Hadza mean and modal offers were very low like the 


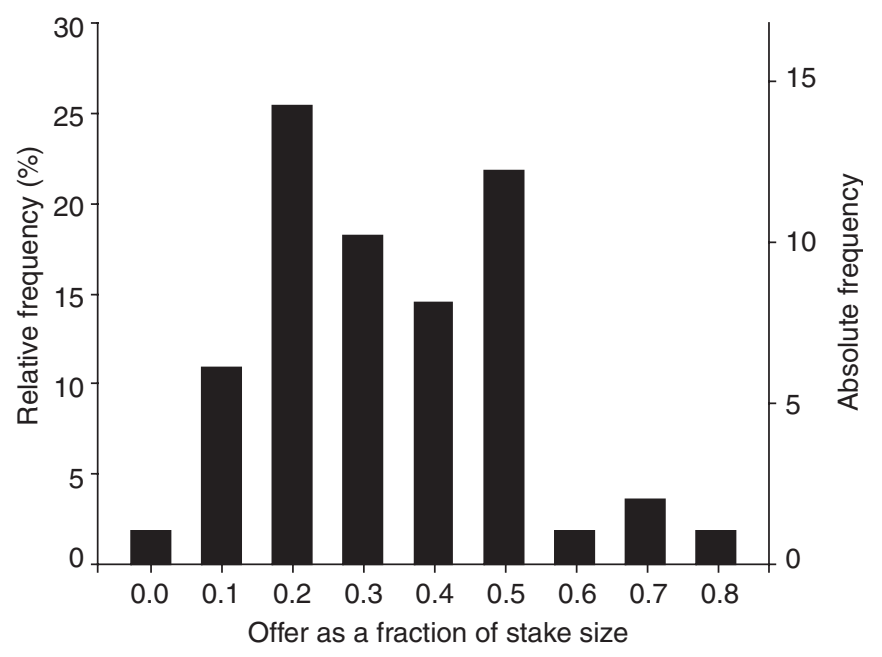

FIG. 6.2. Hadza UG offers

Note: Mode $=0.20$, mean $=0.33, \mathrm{SD}=0.17,13$ rejections.

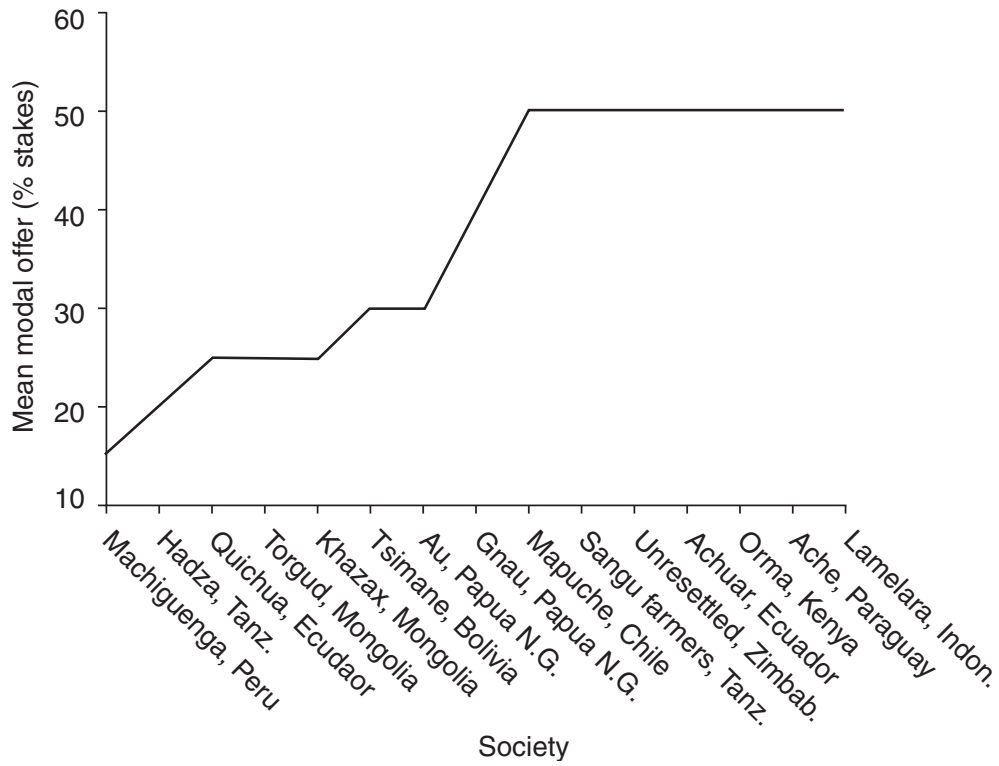

FIG. 6.3. Modal UG offers for all fifteen small-scale societies Note: Mode $=37 \%$, mean $=39 \%, \mathrm{SD}=13 \%$. 


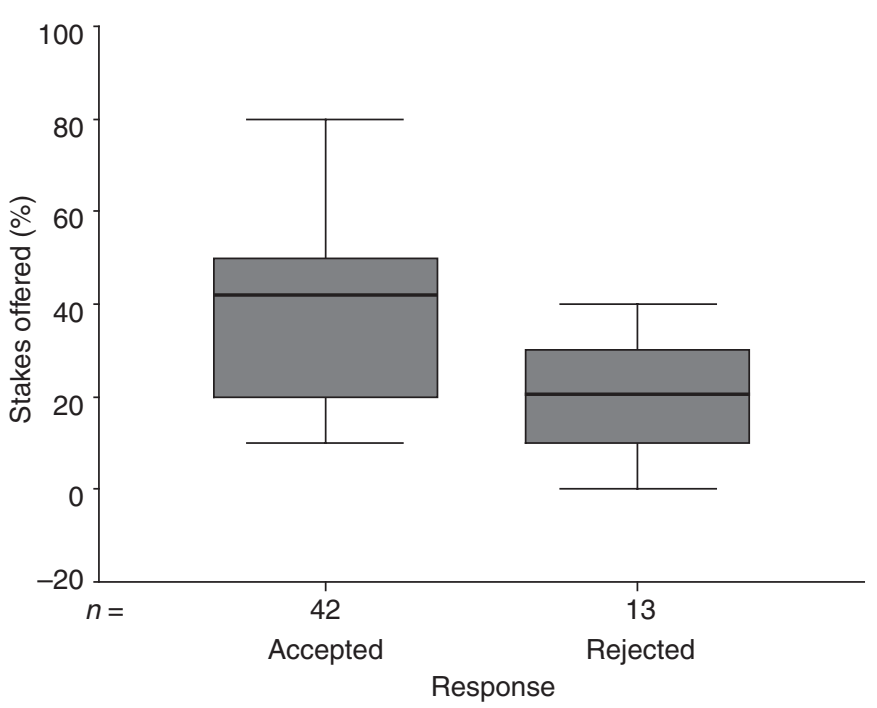

FIG. 6.4. Hadza UG rejections by offer

Note: Rejection rate $=24 \%$, mean rejected offer $=18 \%$.

Machiguenga, the rejection rate was not low. Consequently, Hadza earnings overall were low (mean $=38.1$ percent, range $=0-90$ percent, $\mathrm{SD}=27.5, n=110$ ). The maximum overall earnings possible is 50 percent per person, which would be the case when there were no rejections and group benefit was being maximized.

There were no significant differences in mean offer for males or females (but see below), nor was there any age effect on offers or rejections. There was no effect on offers or rejections due to the number of siblings (but see below) or the number of children one had. Comprehension came close to having a significant effect on offers. There were only three subjects who did not understand well, and nine with an intermediate score, the remaining ninety-eight were scored high on comprehension. Although not significant, those who understood better tended to make higher offers. One might think savvy people would figure out that it is irrational to reject offers above zero and so make low offers. On the other hand, since there were some rejections of offers of 30 percent and even one of 40 percent, savvy people may have had a better understanding of Hadza psychology. 
In a multiple linear regression analysis of age, gender, comprehension, number of siblings, number of children, and camp population, the only significant predictor of offers was camp population (Table 6.1). Offers were higher in larger camps $(\beta=0.475, p=0.000$, $d f=48$ ) (Figure 6.5). Entering comprehension only makes the association between offer and population stronger, showing that the effect was not an artifact of greater comprehension in larger

TABLE 6.1. UG and DG multiple regression results

\begin{tabular}{|c|c|c|c|c|}
\hline \multirow[t]{2}{*}{ Variables } & \multicolumn{2}{|l|}{ Ultimatum } & \multicolumn{2}{|l|}{ Dictator } \\
\hline & $\beta$ & $p$ & $\beta$ & $p$ \\
\hline Age & -0.097 & 0.562 & -0.017 & 0.926 \\
\hline Gender & -0.174 & 0.199 & -0.203 & 0.153 \\
\hline Comprehension & 0.277 & 0.067 & & \\
\hline Number of siblings & 0.010 & 0.943 & -0.196 & 0.162 \\
\hline Number of children & -0.077 & 0.634 & 0.040 & 0.824 \\
\hline Camp population & 0.475 & 0.000 & 0.544 & 0.000 \\
\hline Equation & $R^{2}=0.283$ & $d f=48$ & $R^{2}=0.396$ & $d f=34$ \\
\hline
\end{tabular}

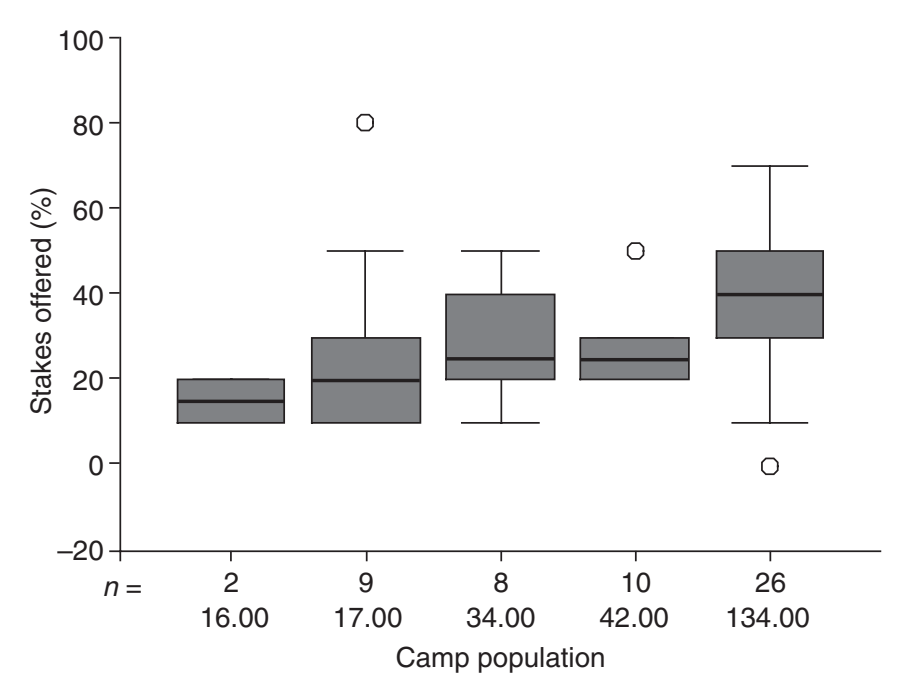

FIG. 6.5. Hadza UG offers by population

Note: $\beta=0.475, p=0.000, d f=48$. 


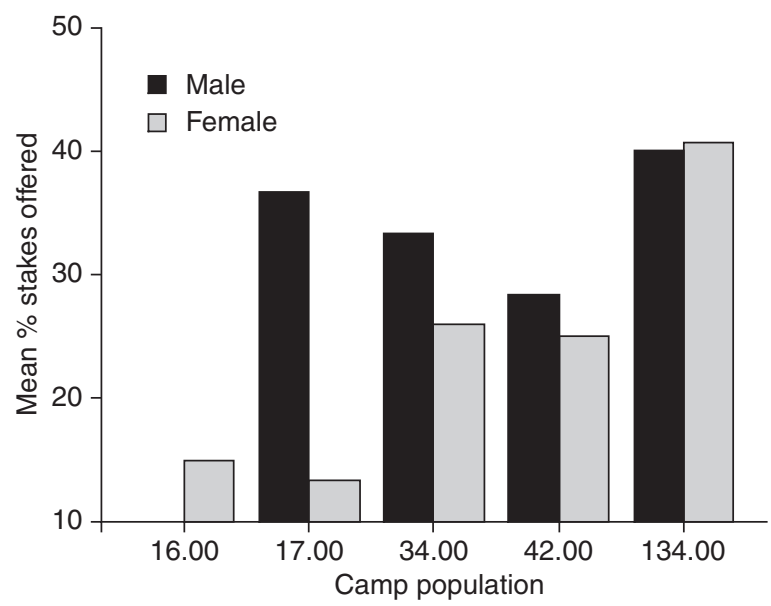

FIG. 6.6. Hadza UG offers by gender by population

Note: Males: $\beta=0.200, p=0.347, d f=21$; females: $\beta=0.628, p=0.000, d f=22$.

camps (in fact, there was no correlation between comprehension and camp population).

Offers by males were not significantly different across camps $(\beta=0.200, p=0.347, d f=21)$, the population effect came mainly from females $(\beta=0.628, p=0.000, d f=22)$ (Figure 6.6). When males and females were analyzed separately, the greater the comprehension, the higher were the offers made by females $(\beta=0.360$, $p=0.019, d f=22)$ but not the offers made by males $(\beta=-0.063$, $p=0.803, d f=21)$. In addition, unlike males, females who had more siblings made lower offers $(\beta=-0.377, p=0.013, d f=22)$.

Because offers were lower in small camps we might expect the overall earnings of proposers and responders to be lower in small camps since overall earnings will drop as the rejection rate increases. However, because there was a slight tendency to accept lower offers in smaller camps, there was no correlation between population and overall earnings $(r=0.097, p=0.316, n=55)$. I found no correlation between population and what responders said was the minimum offer they would have accepted $(r=0.078, p=0.645, n=37)$, but perhaps proposers judged responders well since they got away with offering less in small camps. Still, there was no correlation between proposers' earnings and population $(r=-0.073$, $p=0.596, n=55$ ) but since responders were faced with lower offers 


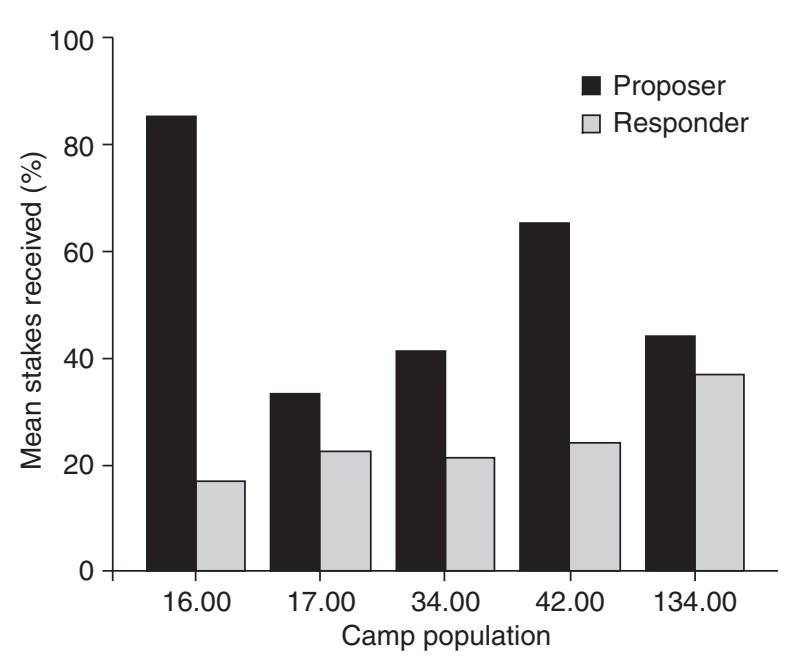

FIG. 6.7. Hadza UG earnings by role and population

Note: Proposers: $r=-0.073, p=0.596, n=55$; responders: $r=0.348, p=0.009, n=55$.

in smaller camps, and to some extent accepted them, responders' earnings were correlated with population $(r=0.348, p=0.009$, $n=55$ ) (Figure 6.7). Proposers earned 18 percent more than responders (47 percent versus 29 percent), a significant difference ( $t=3.61, p=0.000, d f=98.2$, unequal variances).

When the one largest camp (which is much larger than all other camps), is excluded, Hadza offers are much lower (mode $=0.20$, mean $=0.27, \mathrm{SD}=0.16, n=29$ ) (Figure 6.8), and virtually indistinguishable from the Machiguenga offers (mean $=0.26, n=21$ ). The mode is still 0.20 versus 0.15 for the Machiguenga but 0.15 was not an allowed offer for the Hadza. This similarity is interesting because the Machiguenga have typically lived in very small family groups much more similar in population to that of smaller Hadza camps. Given that the largest Hadza camp is unusually large and a fairly recent development, smaller camps are probably more reflective of Hadza norms.

When only the largest camp is considered, Hadza offers are not that different from complex societies (Hadza mode $=0.50$, mean $=0.40, \mathrm{SD}=0.17, n=26$ ) (Figure 6.9). This is also interesting because the Ache of Paraguay, who were strict hunter-gatherers until the 1970s, gave high offers, and they now live in a mission 


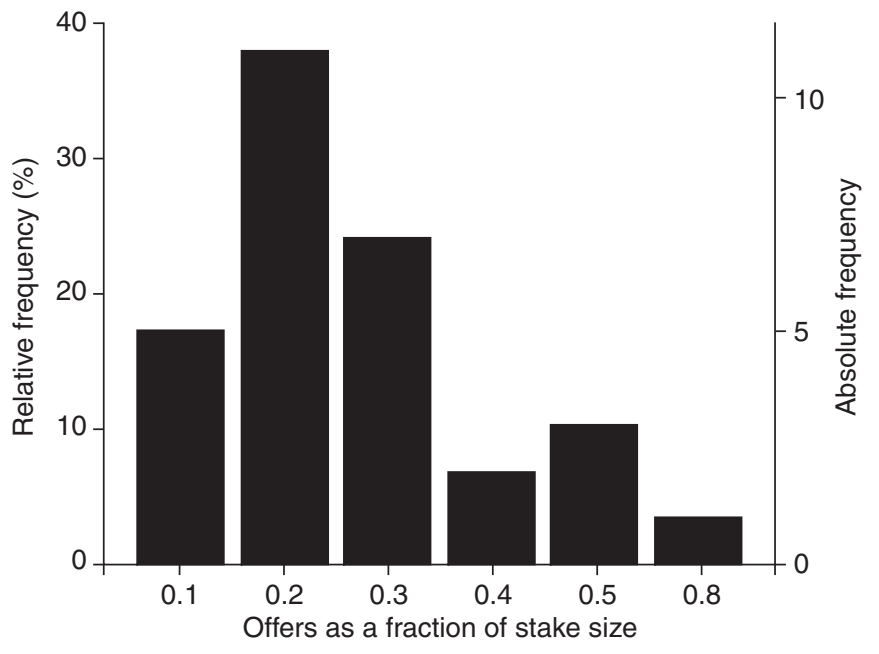

FIG. 6.8. Hadza UG offers in the four smallest camps Note: Mode $=0.2$, mean $=0.27, \mathrm{SD}=0.16, n=29$.

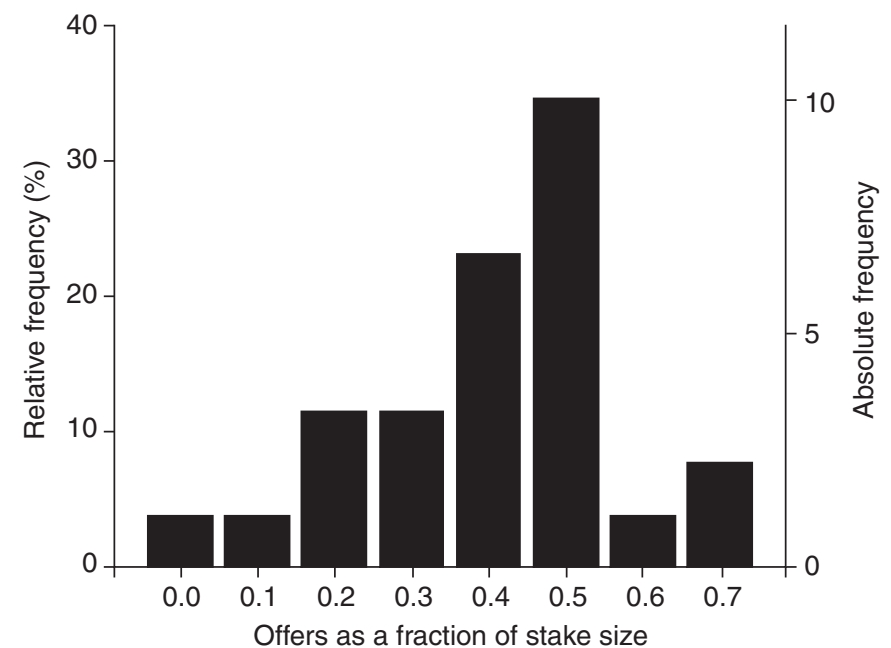

FIG. 6.9. Hadza UG offers in the one largest camp Note: Mode $=0.5$, mean $=0.4, \mathrm{SD}=0.17, n=26$. 
Did you refer to ch. 2. Pls check as ch. 1 i also by Henrich et al
182

Frank Marlowe

settlement with a large enough population that we would expect such high offers, even by Hadza standards.

When offers of only 20 percent or less are considered, there was a higher probability of rejection in the largest camp, four of five versus five of sixteen in all the smaller camps combined (MannWhitney $U=20.5, p=0.061, n=21$ ) (Figure 6.10). This suggests there may have been a higher likelihood of rejecting low offers in larger camps and that proposers were making rational offers.

It is interesting that of all the societies we tested, the Hadza came closest to making income-maximizing offers (IMO) (see Chapter 1). Using IMOs to calculate a value of risk proneness or avoidance where $r=1$ means subjects were risk neutral, we see that most societies were extremely risk avoiding and made offers far higher than needed to avoid rejection (Figure 6.11). Even the low offers of the Machiguenga were too high. On the other hand, Hadza proposers were almost risk neutral $(r=0.94)$ (Henrich et al. Chapter 2, this volume), and it paid off for most of them. Although making low offers was risky because Hadza responders were quite willing to reject, 47.3 percent of proposers nonetheless earned over 50 percent of the stakes (Figure 6.12).

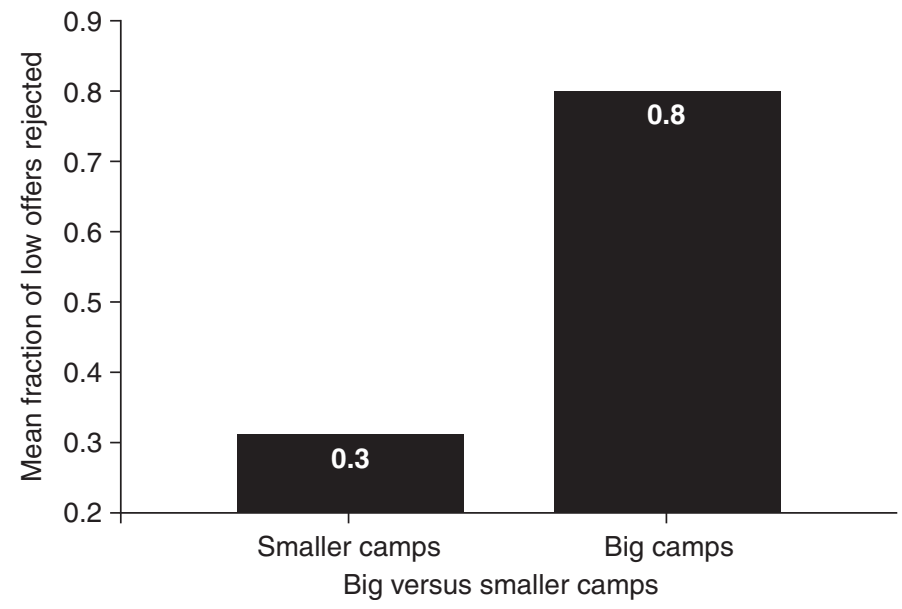

FIG. 6.10. Hadza rejections of UG offers of $\leq 20 \%$, big versus smaller camps

Note: Rejection of offers of $0,0.1$, and 0.2 (5/16 versus 4/5); Mann-Whitney $U=20.5$, $p=0.061, n=21$. 


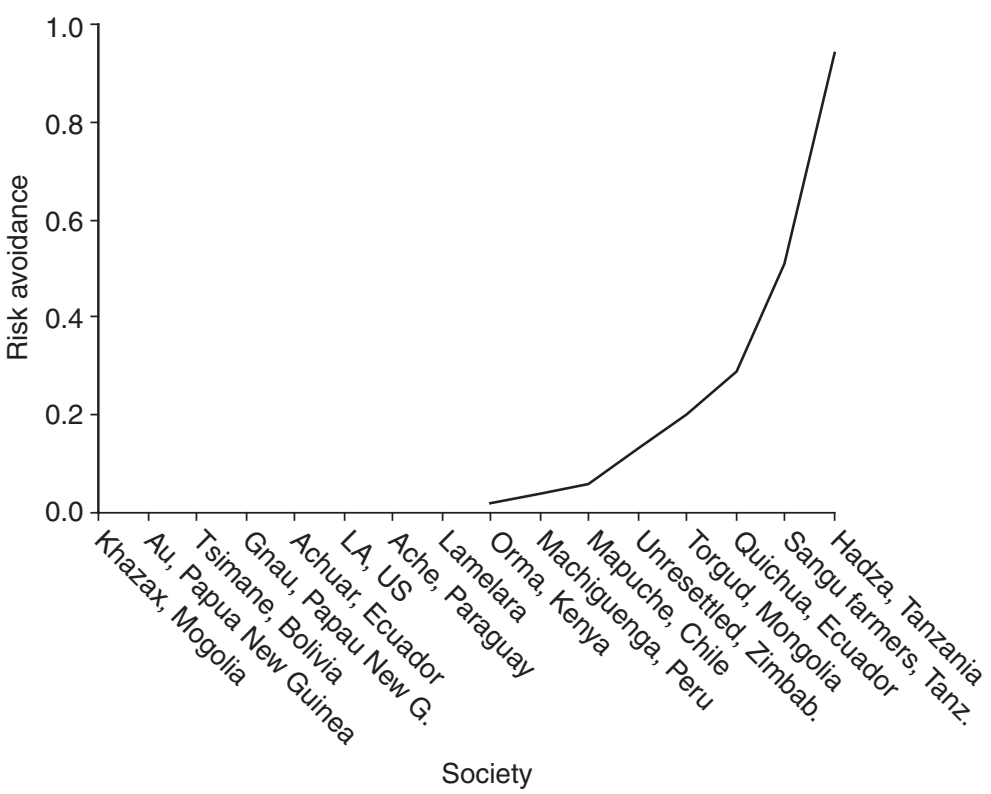

FIG. 6.11. UG risk avoidance in sixteen societies $(0=$ risk avoiding, $1.0=$ risk neutral)

Note: Risk aversion: $0.02-0.94$, hada $=0.94$, big $=0.3$, smaller $=1.0$.

\begin{tabular}{|c|c|c|c|c|c|}
\hline \multicolumn{6}{|c|}{ Percent paid } \\
\hline & & Frequency & Percent & $\begin{array}{c}\text { Valid } \\
\text { percent }\end{array}$ & $\begin{array}{c}\text { Cumulative } \\
\text { percent }\end{array}$ \\
\hline \multirow[t]{4}{*}{ Valid } & 90.00 & 1 & 1.8 & 1.8 & 1.8 \\
\hline & 80.00 & 11 & 20.0 & 20.0 & 21.8 \\
\hline & 70.00 & 6 & 10.9 & 10.9 & 32.7 \\
\hline & 60.00 & 8 & 14.5 & 14.5 & 47.3 \\
\hline & 50.00 & 12 & 21.8 & 21.8 & 69.1 \\
\hline & 40.00 & 1 & 1.8 & 1.8 & 70.9 \\
\hline & 30.00 & 2 & 3.6 & 3.6 & 74.5 \\
\hline & 20.00 & 1 & 1.8 & 1.8 & 76.4 \\
\hline & 00.00 & 13 & 23.6 & 23.6 & 100.0 \\
\hline & Total & 55 & 100.0 & 100.0 & \\
\hline
\end{tabular}

FIG. 6.12. Payoffs to hadza UG proposers $(47.3 \%$ earned $\geq 60 \%$ of the stakes) 


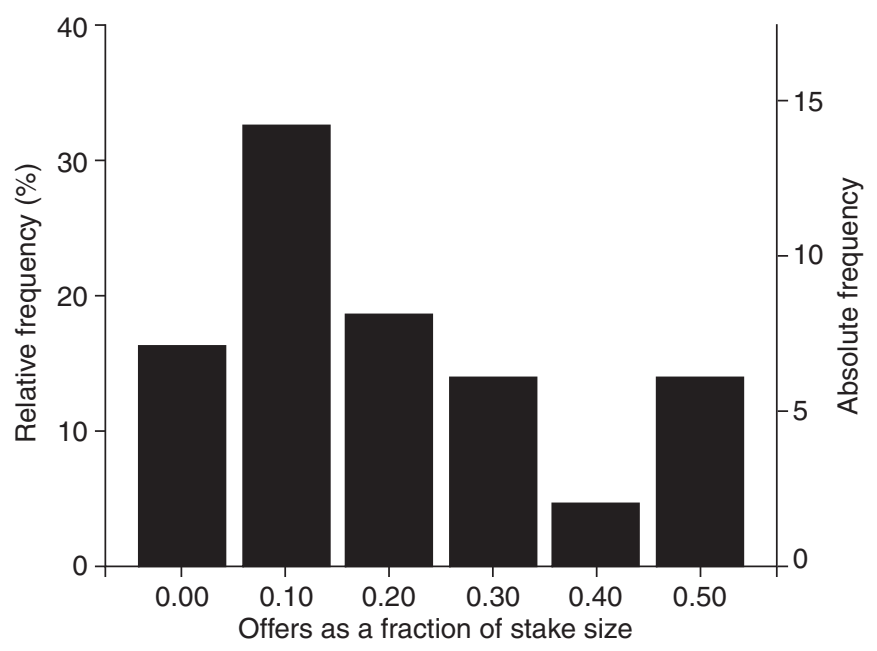

FIG. 6.13. Hadza DG offers

Note: Mode $=0.1$, mean $=0.2, \mathrm{SD}=0.16, n=43$.

\section{The Dictator Game}

In the DG, there were forty-three pairs. Among the proposers, twenty-two were male, twenty-one were female, and mean age was $36.6(17-68, \mathrm{SD}=15.7)$. In complex societies, the modal offer in the DG is between $0.31-0.50$, with a mean of $0.15-0.25$ (Camerer 2003). The modal offer for the Hadza was 0.10 (mean $=20$ percent, $\mathrm{SD}=16.2, n=43$ ) (Figure 6.13). Again the Hadza mode was less than the mean, the opposite of complex societies.

In a multiple linear regression analysis of age, gender, number of siblings, number of children, and camp population, the only significant predictor of offers was again camp population $(\beta=0.544$, $p=0.000, d f=34$ ) (Table 6.1) (Figure 6.14). The effect of gender was almost significant $(t=1.76, p=0.088, d f=35.1$, unequal variances), with females offering less. In the DG (unlike the UG), the population effect came mainly from males $(\beta=0.630, p=0.007$, $d f=16)$, rather than females $(\beta=0.343, \quad p=0.209, d f=14)$ (Figure 6.15). However, this gender difference is probably an artifact of the sample distribution since there were no female dictators in the largest camp.

Finally, only eighteen subjects were proposers in both the UG and DG. Their offers are almost significantly correlated $(r=0.450$, 


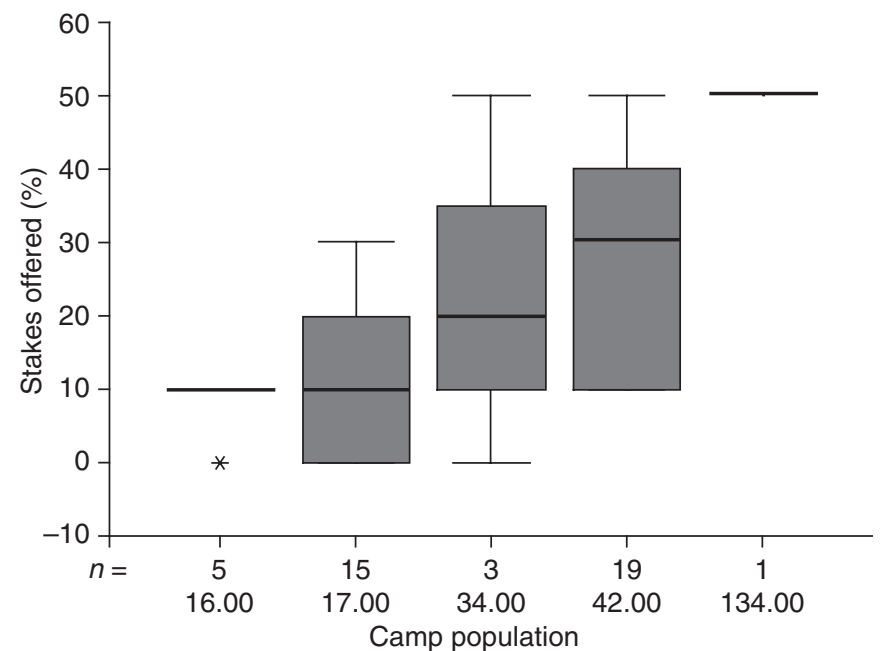

FIG. 6.14. Hadza DG offers by population

Note: $\beta=0.544, p=0.000, d f=34$.

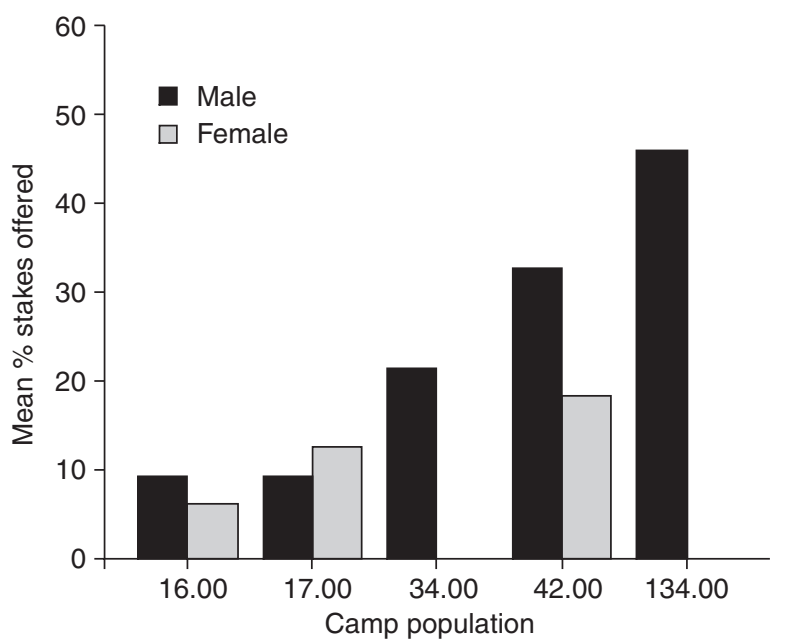

FIG. 6.15. Hadza DG offers by population by gender Note: Males: $\beta=0.630, p=0.007, d f=16$; females: $\beta=0.343, p=0.209, d f=14$. 
$p=0.061, n=18)$. Even though it was the behavior of women overall that was more similar in the two games, in relation to the variable of camp population, it was men's offers in the two games that were more positively related.

\section{DISCUSSION}

The Hadza modal offer of 0.10 in the DG is presumably the extent to which the Hadza are compelled by their own strong sense of fairness to share with others. The modal offer of 0.20 in the UG represents an extra 0.10 due to the threat of rejection. Those who gave 0.5 usually said it was the only fair offer. Those who gave less were quick to pull any old rationalization out of thin air. For example, one said he offered his partner little, 'because he is my good comrade', and another said, 'because my partner is younger than me'. On the other hand, the person who offered 0.8 said they did so, 'because it is in my heart to help a friend'.

The Hadza made lower offers in both the UG and DG than is typical of complex societies. This result is especially interesting given the Hadza can only be described as extremely egalitarian, with a strong sharing ethic. They daily share food, as well as many other items. Americans, on the other hand, usually do not share food on a daily basis with anyone outside the household. We too have a strong sense of fairness that dictates that we share equally-when we do share. But sharing simply does not happen nearly so often in the United States, where privacy and private property are paramount. For the Hadza, living in the open, with no privacy, sharing is a constant, inescapable fact of life. I suggest the difference between the Hadza UG mode of 0.20 and the US UG mode of 0.50 must be related to this never-ending sharing among the Hadza. Perhaps the more frequently one must share, the more weary one grows of it, and the more one looks for any opportunity to escape it.

This same response might also explain why Hadza offers were lower in smaller camps. I have observed that food is more frequently shared outside the household in smaller camps, where everyone usually eats together because there may only be three households and there is absolutely no privacy. Not only have I seen more frequent sharing, I have also seen a wider range of food types being shared. In small camps, for example, even berries, which 
everyone can pick for him or herself, are often shared outside the household. Large camps, where there may be twenty households, are usually broken up into clusters of two or three huts and function somewhat like several small camps. However, there is one important difference. At times, everyone in a large camp is congregated in one spot. This means someone returning to camp can sneak into a hut without his or her food being seen, especially after dark. People in large camps often do just this, asking me to discreetly weigh their food inside to keep others from seeing. In a small camp it is impossible to sneak anything in. Of course, it is also more difficult for any free rider to go unnoticed in a small camp so it may be easier to make reciprocity work.

People may tend to behave more generously when they find themselves in a large camp since the modal UG offer in the largest camp was 0.50 while it was $0.10-0.20$ in all other camps. This may partially explain why large camps even exist. Earnings for responders were higher in large camps, and a similar benefit in real life could be the incentive to move to a large camp. Camp population is an important factor in Hadza life. There is much more bickering in larger camps, as the Hadza so often note. I also found that men provide less direct care to children in larger camps, spending more time with other men instead (Marlowe 1999). Considering that when the largest Hadza camp is excluded, Hadza and Machiguenga offers were equivalent, perhaps overall Machiguenga offers were lower because work-eat groups are smaller, also suggesting group size may be an important factor driving offers.

Originally, I expected offers might be higher in small camps where I had seen more sharing. I also thought stinginess might be greater in large camps because with more possible dyads it would be more difficult for anyone to figure out who their partner was, which would insure greater AN and less concern about one's stinginess being discovered. The opposite was true, which suggests to me there may be a greater fear of punishment in larger camps.

Hadza say people who do not share are bad people and that they will move away from them. Punishment comes in the form of gossip and exile. Among the Hadza's neighbors punishment often comes in the form of accusations of witchcraft. The Hadza do not practice witchcraft but occasionally, if they are upset with another Hadza, the suggestion is made that he has learned witchcraft from neighboring tribes. Being accused of stinginess by several people in a 
large group would be more dangerous than being accused by one or two people in a small group. There is probably more hoarding by everyone in large camps because it is easier to hide food, and I suspect people are more apt to accuse others of stinginess to try to force them to share in large camps, hence, the greater degree of bickering.

Hadza might have offered more in larger camps because they were advertising their generosity. If we assume the game triggers the food sharing context, then even though there was AN, the Hadza may have been responding to population just as they would if the currency was food and there were no AN. Where there are more benefits to be had, more potential mates, for example, we should expect to see more advertisement. We might expect that men stand to gain more than women do from advertising their generosity in larger camps because of a greater potential variation in reproductive success as a function of prestige, but in fact the population effect came mainly from females, at least in the UG. Because the number of free riders should rise with population (Boyd and Richerson 1988), reciprocity predicts people should give higher offers in small groups, contrary to the Hadza results. Nonetheless, reciprocity and costly signaling might explain why DG offers were 10 percent, rather than 0 percent as tolerated scrounging would predict for a perfectly defendable currency.

But how well do these games reflect the behavior involved in food sharing? Money introduced as a windfall might seem different from food that is earned by foraging. However, much food is actually obtained through secondary transfers from someone other than the producer. Such transfers are not unlike a windfall of money to be divided up. There is, however, one important difference between money and many kinds of food; money can more easily be hidden. When a resource can be hidden there is no cost of defending it, so tolerated scrounging predicts the resource will be hoarded.

The Hadza exhibit a high degree of sharing of items they cannot hide like large game, but less sharing of items that can be hidden. Money and beads, which can be hidden, generally do not get shared much. Beads, however, are a durable rather than consumable item and can thus be loaned out and returned, perhaps causing them to be treated differently. Tobacco can be hidden but cannot be smoked in camp without being detected and it is very widely shared when smoked. In fact, I chose not to use tobacco in the games for this very 
reason; there is little motivation to maximize one's income if it cannot be kept.

For the UG proposer who wants to maximize his or her earnings, the crucial question is, 'What is the probability my partner will reject offer X?' To maximize earnings, proposers must risk a higher probability of rejection. How risk-avoiding individuals are should vary with circumstances that determine the utility of a particular resource. If a risk-avoiding strategy guarantees a steady supply of food, for example, but only at a level below that required for survival, a risk-prone strategy will be selected for (Krebs and Davies 1993).

The UG has nothing to do with risk for the responder, but in real life with repeated interactions, there is a chance that spitefully and angrily rejecting low offers now will force others to give larger shares in the future. The all-or-nothing nature of the responder's decision in the UG does not translate well to Hadza reality. For example, when food is shared among the Hadza, rather than simply accepting whatever initial offer is made, people normally hold out a hand, encouraging the giver to keep giving until the giver finally draws the line.

The most puzzling thing about the UG to rational theorists is why responders would reject any offer above zero. However, the logic that, 'something is better than nothing', evaluates resources only in terms of absolute gains. In many contexts, people appear to assess their welfare in relative, rather than absolute terms. For example, a person may get angry if he or she is the only one who does not get a raise even though they get no less money than they did before.

In many situations it is probably adaptive to assess welfare relatively since Darwinian fitness is relative. Spite makes sense if the endgame is relative success. People may use a conditional strategy to evaluate their welfare in relative or absolute terms depending on the circumstances. When the benefit of an absolute gain would ultimately add less to one's fitness than preventing another from gaining the upper hand, people may behave in a way that only appears to be spiteful but is actually rational. Perhaps this explains the seemingly spiteful, but ultimately rational, behavior of responders in the UG. And given the tendency for responders to reject low offers, the high offers of proposers are also not irrational, at least when, like Hadza offers, they are not exceedingly high. 


\section{CONCLUSION}

Food sharing is often attributed to a lack of storage ability among foragers. If meat is going to rot and be worthless, why not give it away. This explanation simply will not suffice for the two reasons described earlier: (1) Hadza eat very rotten meat, and (2) they know how to dry and preserve meat. It also does not explain the widespread sharing of honey, which does not spoil. Assuming that playing for money in these games does tell us something about what motivates food sharing, we can draw some tentative conclusions. Tolerated scrounging predicts that people should give 0 percent in the DG if they can hide their winnings. Instead, the Hadza most often gave 10 percent, suggesting sharing is not completely due to tolerated scrounging.

On the other hand, even though they are egalitarian with a strong sharing ethic, the Hadza were not reluctant to hoard. They were also not reluctant to punish others for hoarding. In evolutionary perspective, such a seeming contradiction makes perfect sense. People should try to keep as much as possible for themselves and their family, while demanding as much as possible from others, as tolerated scrounging predicts. But one thing must be made clear. The Hadza are very generous. Just because those of us working with them have described their sharing as tolerated scrounging or demand sharing does not mean it is rife with grumbling. Tolerated scrounging does not mean the Hadza steal food. On the contrary, the Hadza do not steal anything at all, except from other species. Most food is simply not classified as private property, so it cannot be stolen. Once seen, food must be shared. At first glance, one would think all this sharing is motivated by altruism. But as generous as it appears, we know that the persistent demand to share can wear one out. We get worn out and so do the Hadza, which one observes only after being there a while and being privy to it.

I suggest the Hadza results are explained by a combination of a greater fear of punishment in larger camps (even when there is AN), and a greater desire to escape from constant sharing in smaller camps. In addition to tolerated scrounging, reciprocity and costly signaling are supported by the results to some extent and I suspect all three are involved. Hadza sharing is ubiquitous because there is no status differentiation and no privacy, which means that others 
can demand shares. Private property and privacy in complex societies allows us to escape from such demand sharing.

\section{REFERENCES}

Bahuchet, S. (1990). 'Food sharing among the Pygmies of Central Africa', African Study Monographs, 11(1), 27-53.

Bird, R. (1999). 'Cooperation and conflict: The behavioral ecology of the sexual division of labor', Evolutionary Anthropology, 8(2), 65-75.

Blurton-Jones, N. G. (1984). 'Selfish origin for human food sharing: Tolerated theft', Ethology and Sociobiology, 5, 1-3.

(1987). 'Tolerated theft: Suggestions about the ecology and evolution of sharing, hoarding, and scrounging', Social Science Information, 26, $31-54$.

O'Connell, J., Hawkes, K., Kamuzora, C. L., and Smith, L. C. (1992). 'Demography of the Hadza, an increasing and high density population of savanna foragers', American Journal of Physical Anthropology, 89, 159-81.

Boehm, C. (1999). Hierarchy in the Forest: The Evolution of Egalitarian Behavior. Cambridge: Harvard University Press.

Boyd, R. and Richerson, P. J. (1988). 'The evolution of reciprocity in sizeable groups', Journal of Theoretical Biology, 132, 337-56.

Camerer, C. F. (2003). Behavioral Game Theory: Experiments in Strategic Interaction.

Cosmides, L. and Tooby, J. (1992). 'Cognitive adaptation for social exchange', in J. Barkow, L. Cosmides, and J. Tooby (eds), The Adapted Mind, Oxford: Oxford University Press, pp. 163-228.

Hawkes, K. and Bliege Bird, R. (2002). 'Showing off, handicap signaling, and the evolution of men's work', Evolutionary Anthropology, 11, $58-67$.

O'Connell, J., and Blurton Jones, N. G. (2001). 'Hadza meat sharing', Evolution and Human Behavior, 22, 113-42.

Henrich, J. (2000). 'Does culture matter in economic behavior? Ultimatum game bargaining among the Machiguenga Indians of the Peruvian Amazon', American Economic Review, 90, 973-9.

Isaac, G. (1978). 'The food-sharing behavior of protohuman hominids', Scientific American, 238, 90-108.

Kaplan, H. and Hill, K. (1985). 'Food sharing among Ache foragers: Tests of explanatory hypotheses', Current Anthropology, 26(2), 223-46.

Kitanishi, K. (1998). 'Food sharing among the Aka hunter-gatherers in northeastern Congo', African Studies Monographs, 25, 3-32.

Krebs, J. R. and Davies, N. B. (1993). An Introduction to Behavioural Ecology. Oxford: Blackwell. 
Lee, R. B. (1984). The Dobe !Kung. New York: Holt Rinehart and Winston.

Mabulla, A. Z. P. (1996). Middle and Later Stone Age Land-Use and Lithic Technology in the Eyasi Basin, Tanzania. Unpublished Ph.D., University of Florida.

Marlowe, F. (1999). 'Male care and mating effort among Hadza foragers', Behavioral Ecology and Sociobiology, 46, 57-64.

(2002). 'Why the Hadza are still hunter-gatherers', in S. Kent (ed.), Ethnicity, Hunter-Gatherers, and the 'Other': Association or Assimilation in Africa, Washington: Smithsonian Institution Press, pp. 247-75. . What explains Hadza food sharing?

McGrew, W. C. and Feistner, T. C. (1992). 'Two nonhuman primate models for the evolution of human food sharing: Chimpanzees and Callitrichids', in J. H. Barkow, L. Cosmides, and J. Tooby (eds), The Adapted Mind, Oxford: Oxford University Press.

Newman, J. L. (1995). The Peopling of Africa: A Geographic Interpretation. New Haven: Yale University Press.

Peterson, N. (1993). 'Demand sharing: Reciprocity and the pressure for generosity among foragers', American Anthropologist, 95, 860-74.

Smith, E. A. (1985). 'Inuit foraging groups: Some simple models incorporating conflicts of interest, relatedness, and central-place sharing', Ethology and Sociobiology, 6, 27-47.

Sutton, J. E. G. (1989). 'Toward a history of cultivating the fields', Azania, 21, 27-48.

Wiessner, P. (1982). 'Risk, reciprocity and social influences on !Kung San economies', in L. Eleanor and R. B. Lee (eds), Politics and History in Band Society, Cambridge: Cambridge University Press, pp. 61-81.

Woodburn, J. (1982). 'Egalitarian societies', Man, 17(3), 431-51.

(1998). 'Sharing is not a form of exchange: An analysis of propertysharing in immediate-return hunter-gatherer societies', in C. M. Hann (ed.), Property Relations: Renewing the Anthropological Tradition, Cambridge: Cambridge University Press, pp. 48-63. 